\title{
In vitro Analysis of the Intradiscal Pressure of the Thoracic Spine
}

\author{
Hans-Joachim Wilke*, Andrea Herkommer, Karin Werner and Christian Liebsch \\ Institute of Orthopaedic Research and Biomechanics, Trauma Research Centre UIm, Ulm University, Ulm, Germany
}

The hydrostatic pressure of the nucleus pulposus represents an important parameter in the characterization of spinal biomechanics, affecting the segmental stability as well as the stress distribution across the anulus fibrosus and the endplates. For the development of experimental setups and the validation of numerical models of the spine, intradiscal pressure (IDP) values under defined boundary conditions are therefore essential. Due to the lack of data regarding the thoracic spine, the purpose of this in vitro study was to quantify the IDP of human thoracic spinal motion segments under pure moment loading. Thirty fresh-frozen functional spinal units from 19 donors, aged between 43 and 75 years, including all segmental levels from T1-T2 to T11-T12, were loaded up to $7.5 \mathrm{Nm}$ in flexion/extension, lateral bending, and axial rotation. During loading, the IDP

OPEN ACCESS

Edited by:

Marwan El-Rich

Khalifa University, United

Arab Emirates

Reviewed by:

Dennis Anderson,

Harvard Medical School,

United States

Francesco Travascio,

University of Miami, United States

*Correspondence:

Hans-Joachim Wilke

hans-joachim.wilke@uni-ulm.de

Specialty section: This article was submitted to Biomechanics,

a section of the journal Frontiers in Bioengineering and Biotechnology

Received: 16 April 2020 Accepted: 20 May 2020

Published: 17 June 2020

Citation:

Wilke H-J, Herkommer A, Werner K and Liebsch C (2020) In vitro Analysis of the Intradiscal Pressure of the Thoracic Spine. Front. Bioeng. Biotechnol. 8:614. doi: 10.3389/fbioe.2020.00614 was measured using a flexible sensor tube, which was inserted into the nucleus pulposus under x-ray control. Pressure values were evaluated from third full loading cycles at $0.0,2.5,5.0$, and $7.5 \mathrm{Nm}$ in each motion direction. Highest IDP increase was found in flexion, being significantly $(p<0.05)$ increased compared to extension IDP. Median pressure values were lowest in lateral bending while exhibiting a large variation range. Flexion IDP was significantly increased in the upper compared to the mid- and lower thoracic spine, whereas extension IDP was significantly higher in the lower compared to the upper thoracic spine, both showing significant $(p<0.01)$ linear correlation with the segmental level at $7.5 \mathrm{Nm}$ (flexion: $r=-0.629$, extension: $r=0.500$ ). No significant effects of sex or age were detected, however trends toward higher IDP in specimens from female donors and decreasing IDP with increasing age, potentially caused by fibrotic degenerative changes in the nucleus pulposus tissue. Sagittal and transversal cuttings after testing revealed possible relationships between nucleus pulposus quality and pressure moment characteristics, overall leading to low or negative intrinsic IDP and non-linear pressure-moment behavior in case of fibrotic tissue alterations. In conclusion, this study provides insights into thoracic spinal IDP and offers a large dataset for the validation of numerical models of the thoracic spine.

Keywords: thoracic spine, intradiscal pressure, human intervertebral disc, in vitro study, biomechanics

\section{INTRODUCTION}

The hydrostatic pressure of the nucleus pulposus plays a key role in the biomechanical properties of the thoracic spine, reducing compressive stress gradients in the anulus fibrosus (Stefanakis et al., 2014) and affecting the segmental stability more than any ligamentous or bony structure (Wilke et al., 2020). Several investigators explored the characteristics of intradiscal pressure in 
various in vitro, in vivo, as well as numerical studies, starting with Nachemson, who analyzed the intradiscal pressure in human lumbar spinal specimens (Nachemson, 1959, 1960). Since then, in vitro intradiscal pressure measurements were predominantly performed on the cervical (Pospiech et al., 1999; Dmitriev et al., 2005; Kretzer et al., 2012; Barrey et al., 2015; Liu et al., 2016; Welke et al., 2016; Bell et al., 2018) and lumbar spine (Wilke et al., 1996; Rohlmann et al., 2001; Molz et al., 2003; Schmoelz et al., 2006; Heuer et al., 2007; Gao et al., 2011). On the thoracic spine, in contrast, solely in vivo measurements in mid- and lower thoracic segmental levels (Polga et al., 2004) and few in vitro measurements on specific levels in polysegmental setups (Cheng et al., 2015; Anderson et al., 2016; Metzger et al., 2016) have been conducted so far. For the validation of numerical models and for ensuring high comparability of experimental setups, however, intradiscal pressure data from tests with clearly defined boundary conditions is essential. The purpose of this in vitro study therefore was to quantify the intradiscal pressure in human thoracic spine specimens under pure moment loading.

\section{MATERIALS AND METHODS}

\section{Specimens}

Thirty fresh-frozen human functional spinal units from 19 donors, including at least one specimen per thoracic spinal segmental level, were prepared for experimental testing. Nineteen specimens were from female donors and 11 from male donors, while average donor age was 56 years, ranging from 43 to 75 years (Table 1). Inclusion criteria were sufficient intervertebral disc height and the absence of severe osteophyte formation,

TABLE 1 | Data on donor age (categorized into ranges for anonymization) and segmental levels used for experimental testing.

\begin{tabular}{lll}
\hline Donor no. & Age range in years & Segmental levels \\
\hline 1 & $41-45$ & T1-T2, T6-T7 \\
2 & $41-45$ & T6-T7, T10-T11 \\
3 & $46-50$ & T1-T2 \\
4 & $46-50$ & T2-T3 \\
5 & $46-50$ & T11-T12 \\
6 & $51-55$ & T10-T11 \\
7 & $51-55$ & T7-T8 \\
8 & $51-55$ & T3-T4, T8-T9, T10-T11 \\
9 & $51-55$ & T4-T5, T8-T9 \\
10 & $56-60$ & T2-T3, T6-T7 \\
11 & $56-60$ & T11-T12 \\
12 & $56-60$ & T3-T4, T7-T8 \\
13 & $56-60$ & T6-T7 \\
14 & $61-65$ & T3-T4 \\
15 & $61-65$ & T9-T10, T11-T12 \\
16 & $61-65$ & T10-T11 \\
17 & $61-65$ & T7-T8, T9-T10 \\
18 & $71-75$ & T5-T6, T9-T10, T11-T12 \\
19 & $71-75$ & T9-T10 \\
& &
\end{tabular}

bony, cartilaginous, or ligamentous defects, fractures and tumors, which was confirmed by frontal and sagittal x-rays (Faxitron 43805N, Hewlett Packard, Palo Alto, USA). Additionally, adequate flexibility of the motion segments was proved by manual control after preparation. Specimens were stored at $-20^{\circ} \mathrm{C}$ and were thawed for $12-14 \mathrm{~h}$ prior to preparation and testing, which was kept below $20 \mathrm{~h}$ in total. During preparation, care was taken to preserve all biomechanically relevant structures including all bony, cartilaginous, and ligamentous structures as well as the costovertebral joints, while the ribs were shortened to stumps with a length of about $20-30 \mathrm{~mm}$ and all muscle, fat, and nerve tissue was removed. Both vertebrae of the functional spinal units were embedded half, coaxially, and parallel to the intervertebral disc in polymethylmethacrylate (PMMA, Technovit 3040, Heraeus Kulzer, Wehrheim, Germany), while the center of the vertebral body was tried to be positioned in the cylinder axis of the embedding. Using modeling clay prior to embedding, it was ensured to keep the intervertebral ligaments and facet joints movable. Additionally, screws were driven into the vertebral bodies in order to enhance rigid fixation in the embedding before molding. For biomechanical testing, flanges were fixed coaxially on the PMMA cylinders. Pressure sensors were inserted by injecting cannulae in the center of the anterior side of the intervertebral disc, while care was taken that the measurement port of the sensor was positioned in the center of the nucleus pulposus and pointed in cranial direction in all specimens. Correct positioning of the sensor was verified in all planes using a mobile x-ray system (Exposcop CB7-D, Ziehm, Nuremberg, Germany). For fixation of the pressure sensors, a clamping device was sutured to the anterior longitudinal ligament (Figure 1). In order to avoid specimen disintegration, tissue was kept moist using $0.9 \%$ saline solution during the process of preparation and testing.

\section{Experimental Setup}

Intradiscal pressure measurement was performed using a sensor device with a diameter of $1.2 \mathrm{~mm}$ (FMSPEZ50, MIPM GmbH, Hattenhofen, Germany), including a piezoelectrical micropressure sensor in its metal tip, exhibiting a maximum pressure of $5 \mathrm{MPa}$ and an accuracy of $1 \mathrm{kPa}$. This method had already been successfully applied to the cervical (Pospiech et al., 1999) and lumbar spine (Wilke et al., 1996; Rohlmann et al., 2001; Schmoelz et al., 2006; Heuer et al., 2007) in previous in vitro studies. Before each testing, the sensors were calibrated up to $0.6 \mathrm{MPa}$ using a (Digibar II, HBM GmbH, Darmstadt, Germany). Specimen loading was performed using a well-established spine tester, allowing six-degree-of-freedom quasi-static flexibility testing (Wilke et al., 1994). By means of this technique, range of motion and neutral zone values were already quantified for all thoracic spinal segmental levels in a previous in vitro study (Wilke et al., 2017).

\section{Testing Procedure}

The specimens were loaded up to pure moments of $7.5 \mathrm{Nm}$ with an angular velocity of $1 \%$ in flexion/extension and lateral bending as well as $0.5^{\circ} \mathrm{s}$ in axial rotation. Each test run included 3.5 loading cycles per motion plane, while the third full loading 


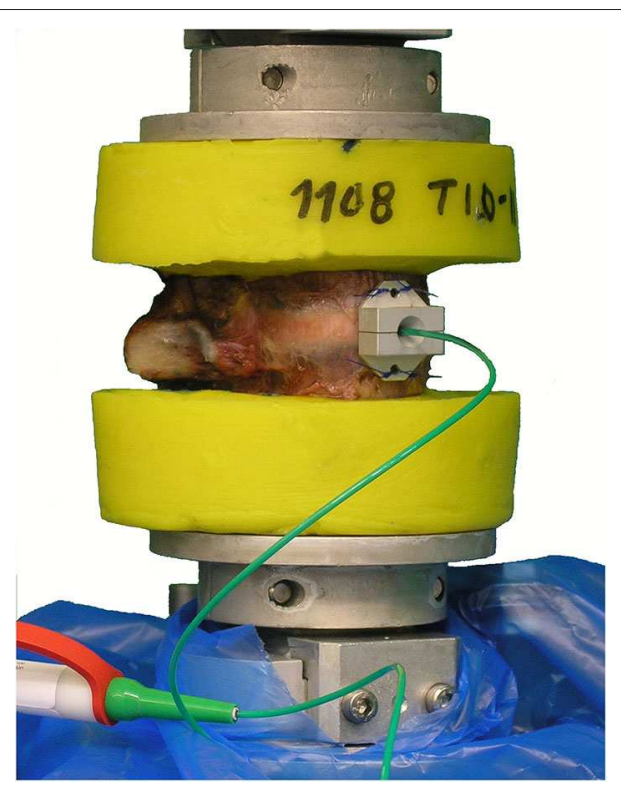

FIGURE 1 | Illustration of the test setup, exemplarily showing a T10-T11 motion segment with implanted intradiscal pressure sensor prior to pure moment loading.

cycle was extracted for data evaluation, while the first to loading cycles served for preconditioning of the intervertebral disc and the ligaments (Wilke et al., 1998). After biomechanical testing, the specimens were cut along the sagittal plane using a diamond band saw EXAKT Advanced Technologies GmbH, Norderstedt, Germany) in order to additionally assess the intervertebral disc quality.

\section{Data Evaluation and Statistics}

Intradiscal pressure and moment loading data was postprocessed using Microsoft Excel 2016 (Microsoft Corp., Redmond, USA) and evaluated regarding pressure values at predefined pure moments of $0.0,2.5,5.0$, and $7.5 \mathrm{Nm}$ in all motion directions (Figure 2) using Matlab 2014b (MathWorks Inc., Natick, USA). Statistical significances and correlations were analyzed using SPSS 24 (IBM Corp., Armonk, USA). Two group comparisons (effect of sex) were performed using the Mann-Whitney $U$-test, while multiple group comparisons were conducted using either Friedman's ANOVA in case of dependent samples (differences between pressure values for same applied moments among all motion directions and between pressure values in every motion direction for all applied moments) or the Kruskal-Wallis test with Bonferroni-Dunn correction in case of independent samples (differences between thoracic spinal regions for same applied moments and motion directions), each with a significance level of 0.05 . Linear correlation analysis was performed for the effect of segmental level and age on the intradiscal pressure using Pearson's r, while the significance level was set to 0.01 . In case of significant correlation, linear regression analysis was additionally conducted to detect potential linear relationships between the respective parameters.

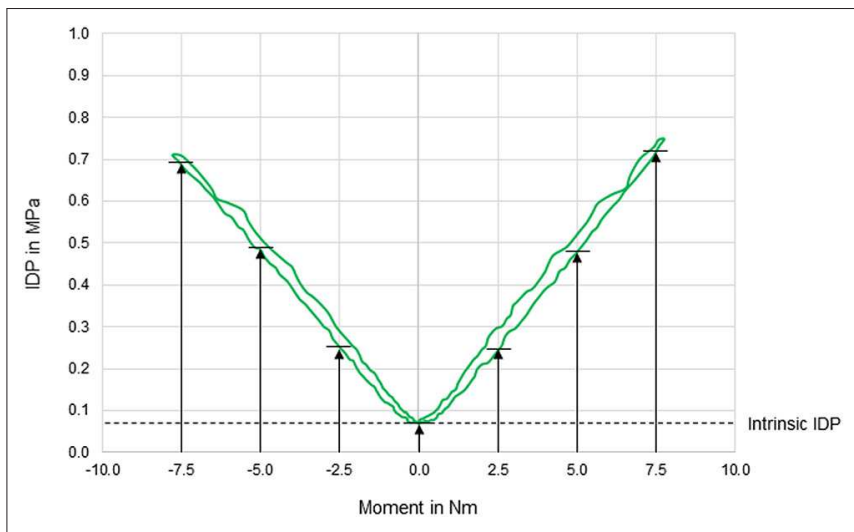

FIGURE 2 | Exemplary diagram illustrating the intradiscal pressure (IDP) as a function of applied moment in lateral bending of a T11-T12 motion segment. IDP was quantified at pure moments of $0 \mathrm{Nm}$ (intrinsic intradiscal pressure), $2.5,5$, and $7.5 \mathrm{Nm}$ for each motion direction.

\section{Ethics, Funding, and Conflicts of Interest}

The use of human specimens was approved by the ethical committee board of the University of Ulm, Germany, in November 2014 (No. 302/14). The specimens were acquired from the body donation organizations Anatomy Gifts Registry program (AGR, Hanover, Maryland, USA) and Science Care (Science Care Inc., Phoenix, Arizona, USA), which declared that written informed consent of the donors was obtained prior to decease. The study was funded by the German Research Foundation (DFG, WI1352/20-2). The authors declare to have no potential conflicts of interest.

\section{RESULTS}

In general, pressure-moment curves exhibited symmetrical, Vshaped characteristics (Figure 2), especially in axial rotation. Intradiscal pressure was generally highest in flexion movement at the pure moment of $7.5 \mathrm{Nm}$, which represented a significant increase compared to extension and right lateral bending for the same applied moment (Figure 3). Furthermore, the intradiscal pressure significantly increased for all applied moments compared to all previous steps in flexion direction, which was also found for bilateral axial rotation with the exception of the intradiscal pressure at $2.5 \mathrm{Nm}$ in right axial rotation. Significant increases of the intradiscal pressure were also found for all loading steps in extension and at an applied moment of $5.0 \mathrm{Nm}$ in left lateral bending, each compared to the intrinsic intradiscal pressure at $0.0 \mathrm{Nm}$. Median intrinsic pressure was below $0.06 \mathrm{MPa}$ in all motion planes, while being significantly increased during lateral bending movement $(0.058 \mathrm{MPa})$ compared to axial rotation $(0.037 \mathrm{MPa})$ and flexion/extension $(0.022 \mathrm{MPa})$. Variation range was generally lowest in axial rotation and flexion, while being highest in lateral bending, where the average $\mathrm{v}$-shape of the pressure-moment curves was rather flattened. In extension, the median intradiscal 

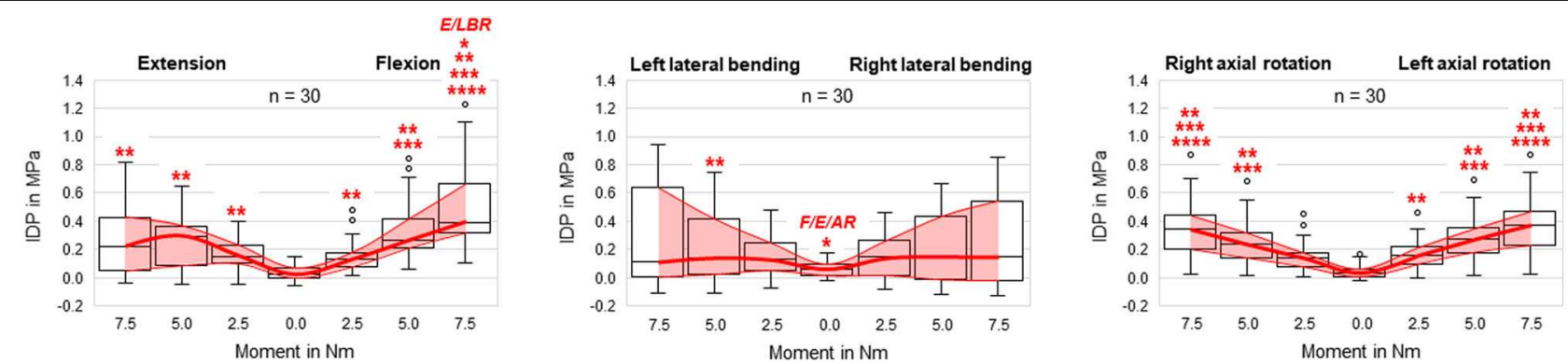

FIGURE 3 | Boxplot diagrams illustrating the intradiscal pressure (IDP) values of all tested specimens $(n=30)$ as a function of the applied moment in the six motion directions, including medians, 25th and 75th percentiles, as well as maximum and minimum values. Outliers are plotted as points. The bold red line represents the connection between all median values, while the red area summarizes the medium 50-percentile zone. Significantly increased IDP values ( $p<0.05)$ are marked by asterisks: " , Significantly higher compared to respective motion directions with same applied moment (F, flexion; E, extension; LB(L/R), (left/right) lateral bending; $\mathrm{AR}(\mathrm{L} / \mathrm{R})$, (left/right) axial rotation); ${ }^{* *}$, Significantly higher compared to intrinsic disc pressure at $0.0 \mathrm{Nm}$ within the same motion direction; ${ }^{* \star *}$, Significantly higher compared to disc pressure at $2.5 \mathrm{Nm}$ within the same motion direction; ${ }^{\star \star \star \star}$, Significantly higher compared to disc pressure at $5.0 \mathrm{Nm}$ within the same motion direction.

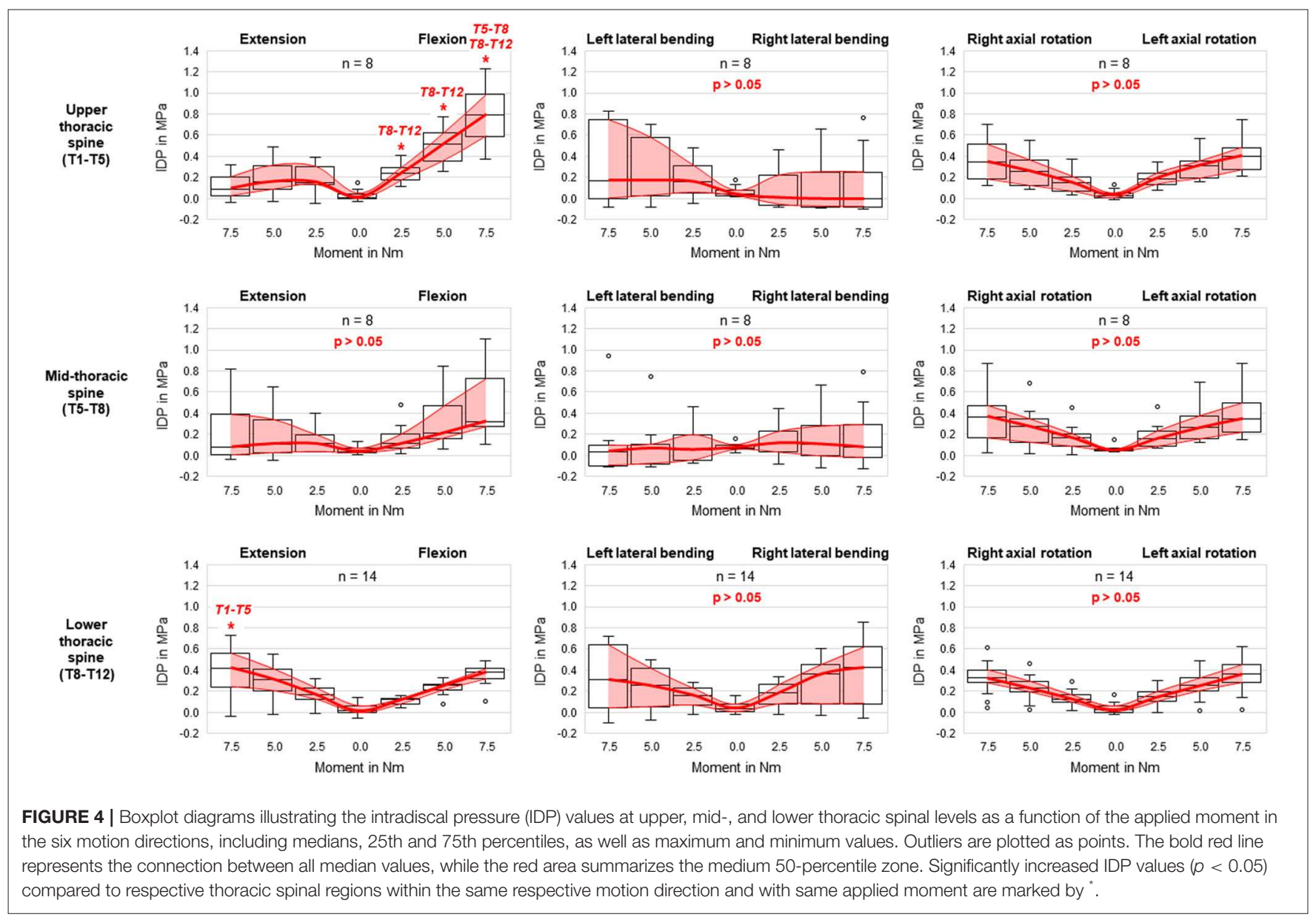

pressure even tended to decrease from 5.0 to $7.5 \mathrm{Nm}$, leading to a non-linear pressure-moment behavior.

Comparing the intradiscal pressure regarding thoracic spinal regions, significantly higher pressures were found in flexion of the upper thoracic spine (T1-T5) compared to the lower thoracic spine (T8-T12) for all loading steps as well as compared to the mid-thoracic spine (T5-T8) at the applied moment of $7.5 \mathrm{Nm}$ (Figure 4). In contrast, the intradiscal pressure in extension was significantly higher in the lower thoracic spine compared to the upper thoracic spine at $7.5 \mathrm{Nm}$. Significant linear correlation was detected between thoracic spinal level in flexion for all applied moments and in extension at $7.5 \mathrm{Nm}$, 


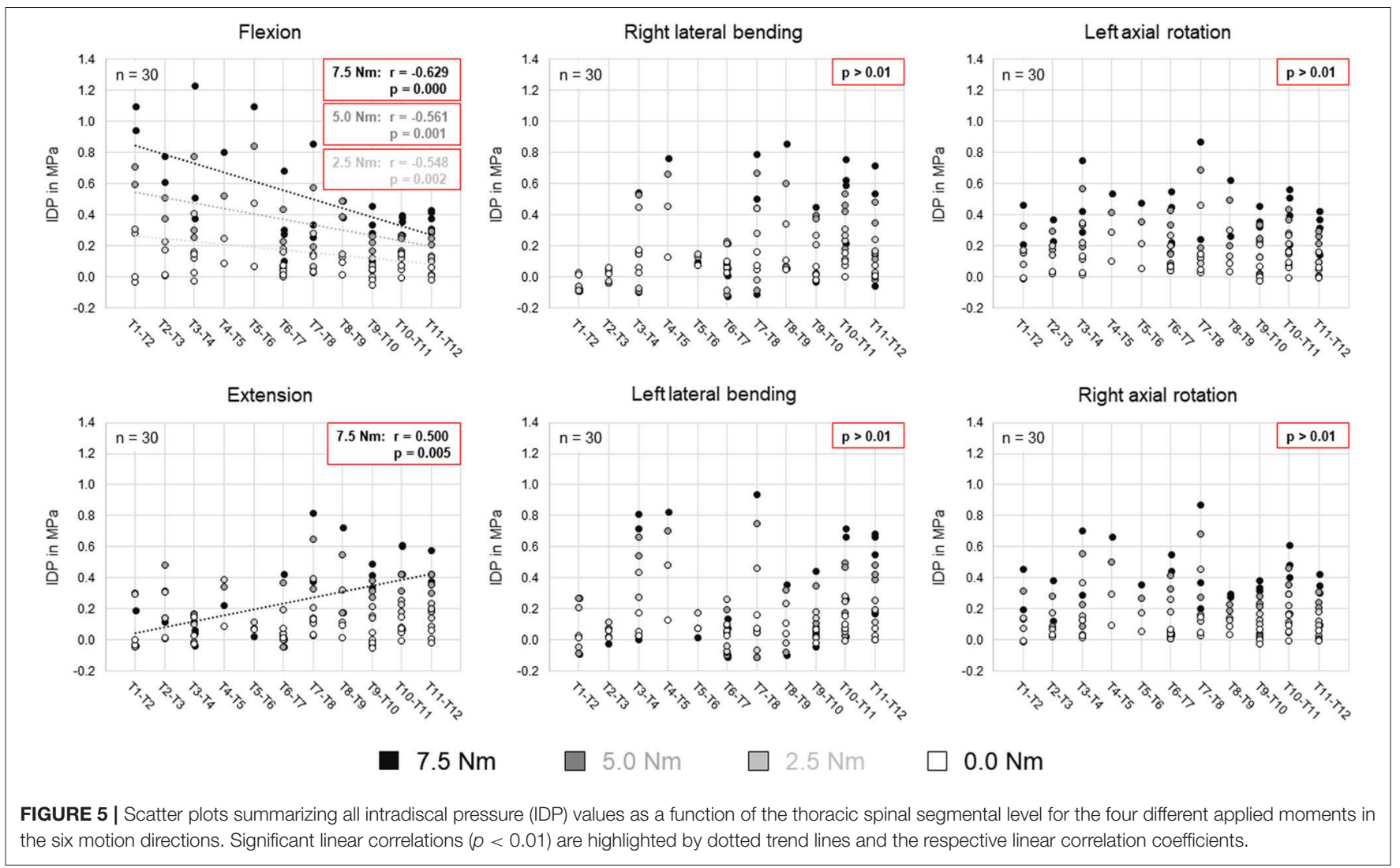

while correlation was generally found being negative in flexion ( $r=-0.629 /-0.561 /-0.548$ for $7.5 / 5.0 / 2.5 \mathrm{Nm}$, respectively) and positive in extension $(r=0.500)$ (Figure 5). Additional regression analysis exhibited an approximate intersection point of intradiscal pressure trend at T12 level with about $0.4 \mathrm{MPa}$ in the flexion/extension motion plane. No significant differences between the single thoracic spinal regions or correlations between the single segmental levels and the intradiscal pressure were found in lateral bending and axial rotation. Variation range tended to be lowest in the lower thoracic spine in case of flexion and axial rotation movements, while it tended to be lowest in the mid-thoracic spine in case of lateral bending movements (Figure 4). In extension direction, the pressuremoment characteristics tended to alter in craniocaudal direction, with the median intradiscal pressure peak tending to shift toward higher applied moments.

No statistical significant effects of sex and age on the intradiscal pressure were found in the present study. However, the intradiscal pressure tended to be higher and exhibited larger variation ranges in specimens from female donors compared to those of male donors (Figure 6). Moreover, slight trends were detected toward decreasing intradiscal pressure with increasing donor age for all applied moments in all motion directions (Figure 7). Although age had no statistically significant effect, indications were found that the intradiscal pressure was affected by the tissue quality of the intervertebral disc. While not showing substantial signs of degeneration in the x-ray images, fibrotic changes of the nucleus pulposus and the anulus fibrosus were especially detected in specimens from elderly donors, overall leading to low or even negative intrinsic pressure and more flattened pressure-moment characteristics compared to specimens from younger donors (Figure 8).

A summary of all evaluated parameters including the statistical analysis is given in the Supplementary Excel file attached to this publication.

\section{DISCUSSION}

The intradiscal pressure of the human thoracic spine has been poorly investigated. While several previous in vivo and vitro studies determined the intradiscal pressure of the cervical and lumbar spine, the hydrostatic pressure in thoracic intervertebral discs was solely explored in a single in vivo study (Polga et al., 2004). For a complete understanding of thoracic spinal biomechanics as well as for the accurate validation of in vitro and numerical models of the thoracic spine, however, data on the thoracic spinal intradiscal pressure is essential. The present in vitro study therefore aimed to quantify the intradiscal pressure of all human thoracic spine segmental levels under multi-planar pure moment loading.

Pressure-moment characteristics revealed a high dependence of the intradiscal pressure on the respective motion direction. While showing almost linear relationship in flexion and bilateral 


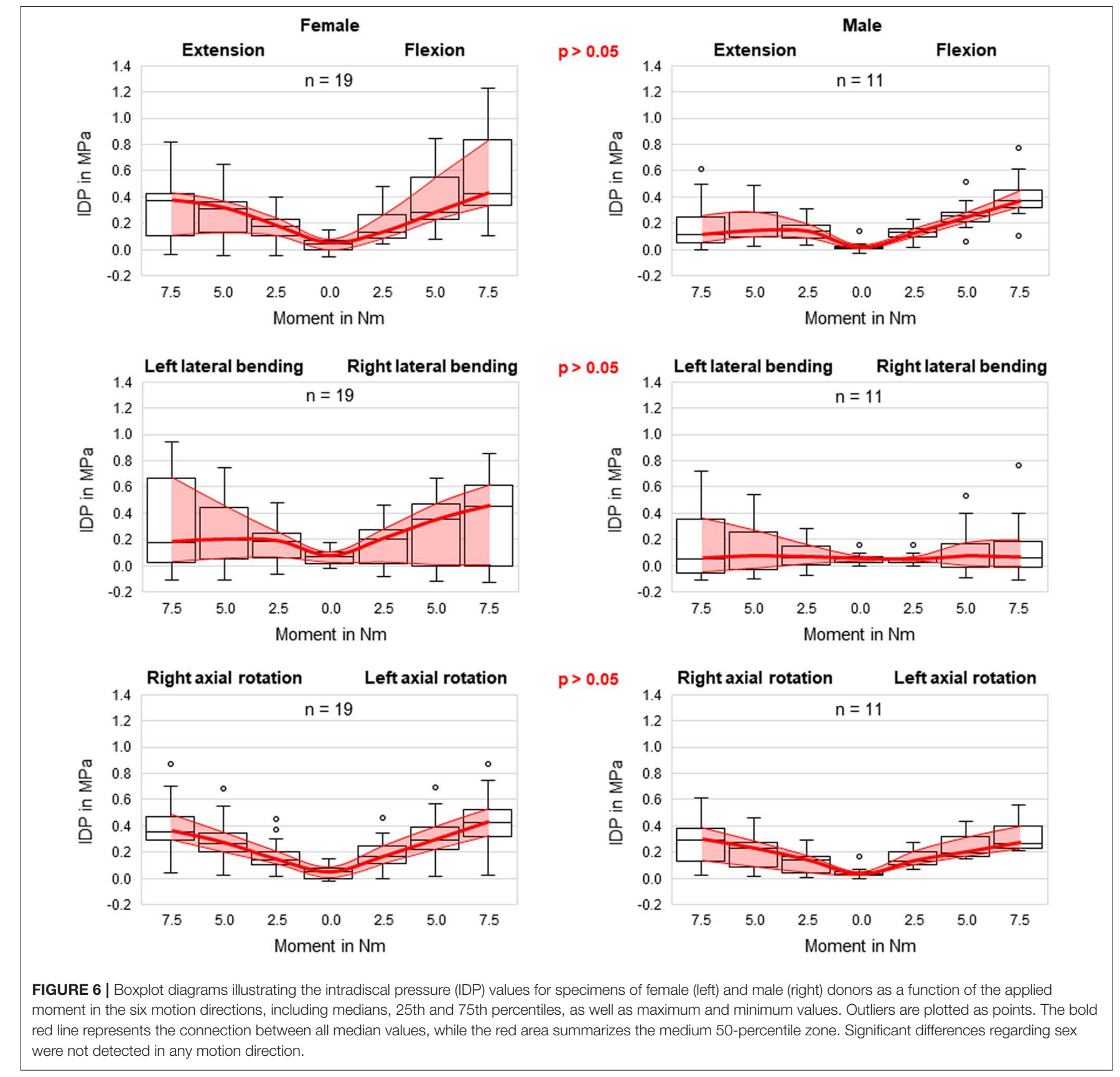

axial rotation, a distinct tendency was found in the upper and mid-thoracic spine toward a non-linear relationship in extension as well as in bilateral lateral bending, respectively. Since all segmental levels were tested under same loading conditions, the non-linear pressure-moment behavior in extension might indicate that in the upper and mid-thoracic spine, physiological loading is generally lower in extension direction compared to the other five motion directions when hypothesizing that the pressure-moment characteristics show linear behavior during elastic deformation of the intervertebral disc. However, due to the fact that the intradiscal pressure even decreased for higher moments in the upper segmental levels, it can be expected that the loads are rather transferred to the facet joints than to the intervertebral disc. Moreover, it was found that the flexion intradiscal pressure significantly decreased from the upper to the lower thoracic segmental levels, whereas the intradiscal pressure significantly increased, while being approximately equal at T12 level, suggesting that the intradiscal pressure divergence between flexion and extension generally decreases toward the thoracolumbar transition region. The pressuremoment characteristics in lateral bending, in contrast, exhibited a high variation range and low median intradiscal pressure 


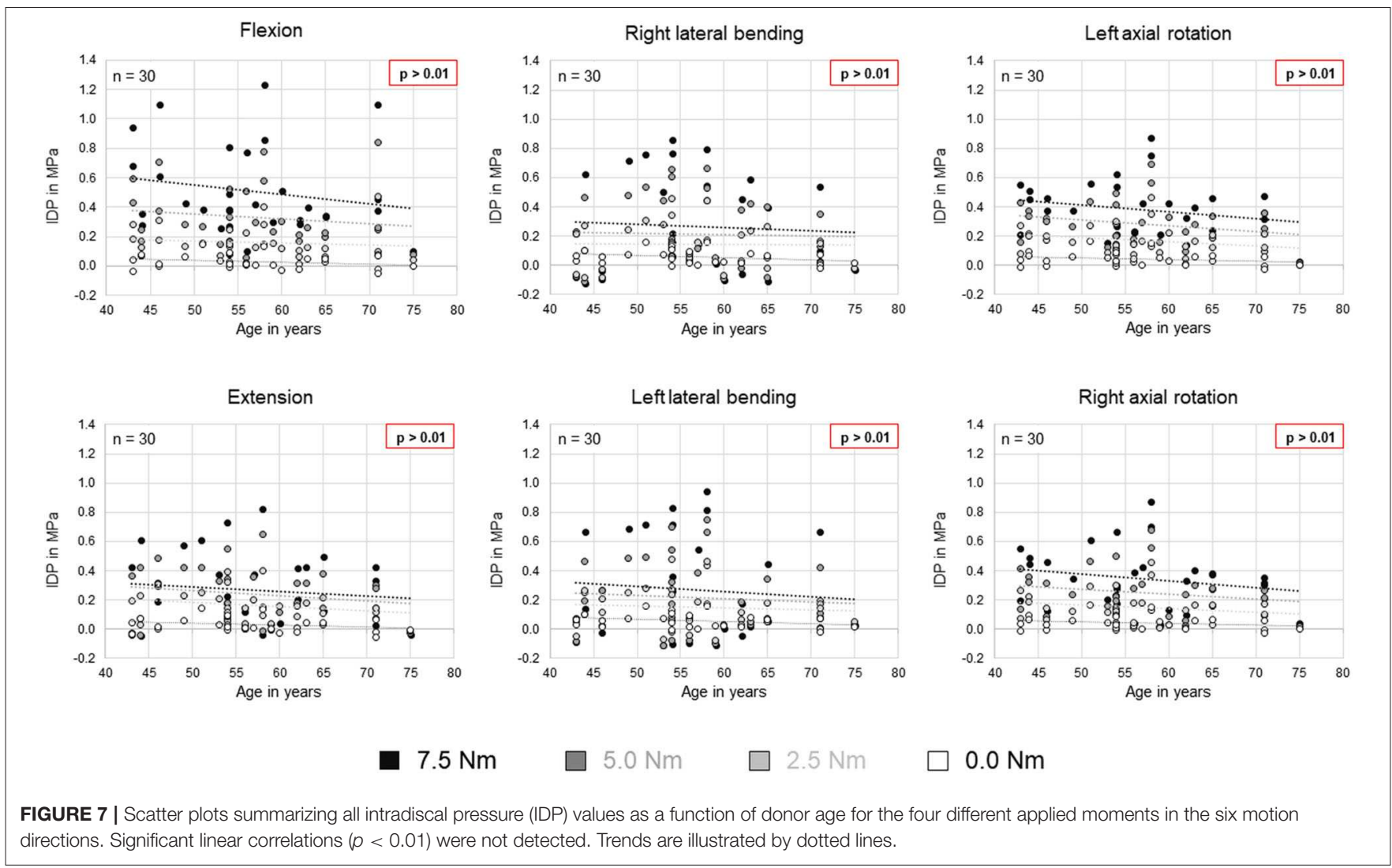

values in the upper and mid-thoracic segmental levels, indicating a high impact of individual intervertebral disc properties on the lateral bending intradiscal pressure, such as degenerative, morphological, or biochemical features. In axial rotation, on the contrary, the pressure-moment characteristics were overall comparable across all segmental levels and revealed a low variation range, indicating a low effect of intervertebral disc properties on the intradiscal pressure during axial torsion. In general, thoracic spinal motion segments showed V-shaped pressure-moment behavior during entire loading cycles in all motion planes in the present study, while previous studies on the lumbar spine exhibited more butterfly-shaped pressuremoment characteristics (Wilke et al., 1996; Rohlmann et al., 2001; Schmoelz et al., 2006). This might indicate that in the thoracic spine, bending and torsion of the intervertebral disc leads to a more homogeneous volumetric compression of the nucleus pulposus compared to the lumbar spine, where the nucleus pulposus has a larger play due to higher deformability of the anulus fibrosus (Koeller et al., 1984). Therefore, the intervertebral disc height, which is greater in the lumbar spine compared to the thoracic spine (Pooni et al., 1986), might essentially contribute to the pressure-moment behavior.

In the present study, intrinsic intradiscal pressure values varied between -0.052 and $0.175 \mathrm{MPa}$ with a median value of $0.037 \mathrm{MPa}$, while not exhibiting any significant effect of segmental level, sex, or age. However, significant effects of the motion plane were found, indicating potential effects of the motion plane on specimen preconditioning, although differences were overall minimal. Data of comparable in vitro studies on the lumbar spine also exhibited higher intrinsic intradiscal pressure in lateral bending compared to flexion/extension and axial rotation (Wilke et al., 1996; Rohlmann et al., 2001; Schmoelz et al., 2006), leading to the assumption that preconditioning in lateral bending might differ from the other two motion planes. Compared to previous in vitro studies on the cervical and lumbar spine, the intrinsic intradiscal pressure values of the present study showed a high variation range, while overall being in the same order of magnitude (Table 2). This large variation range might be explained by effects of intervertebral disc degeneration, which is known to increase with advancing age in the thoracic spine (Goh et al., 2000). Moreover, previous in vitro studies on the lumbar spine found that the intrinsic intradiscal pressure is lower in more degenerated intervertebral discs compared to healthy, young intervertebral discs, which generally show positive pressure values in vitro (Nachemson et al., 1979; Panjabi et al., 1988; Adams et al., 1996). As a consequence, it can be expected that disc degeneration induced the negative pressure values in the present study, although no distinct signs of degeneration were examined on the x-rays prior to the experiments. However, even mildly degenerated intervertebral discs exhibit hydrostatic properties, which was shown in a previous in vitro study on the lumbar spine (Adams et al., 1994). Therefore, specimens with negative pressure values were not excluded from the present study, since the primary aim was to evaluate the intradiscal pressure of 


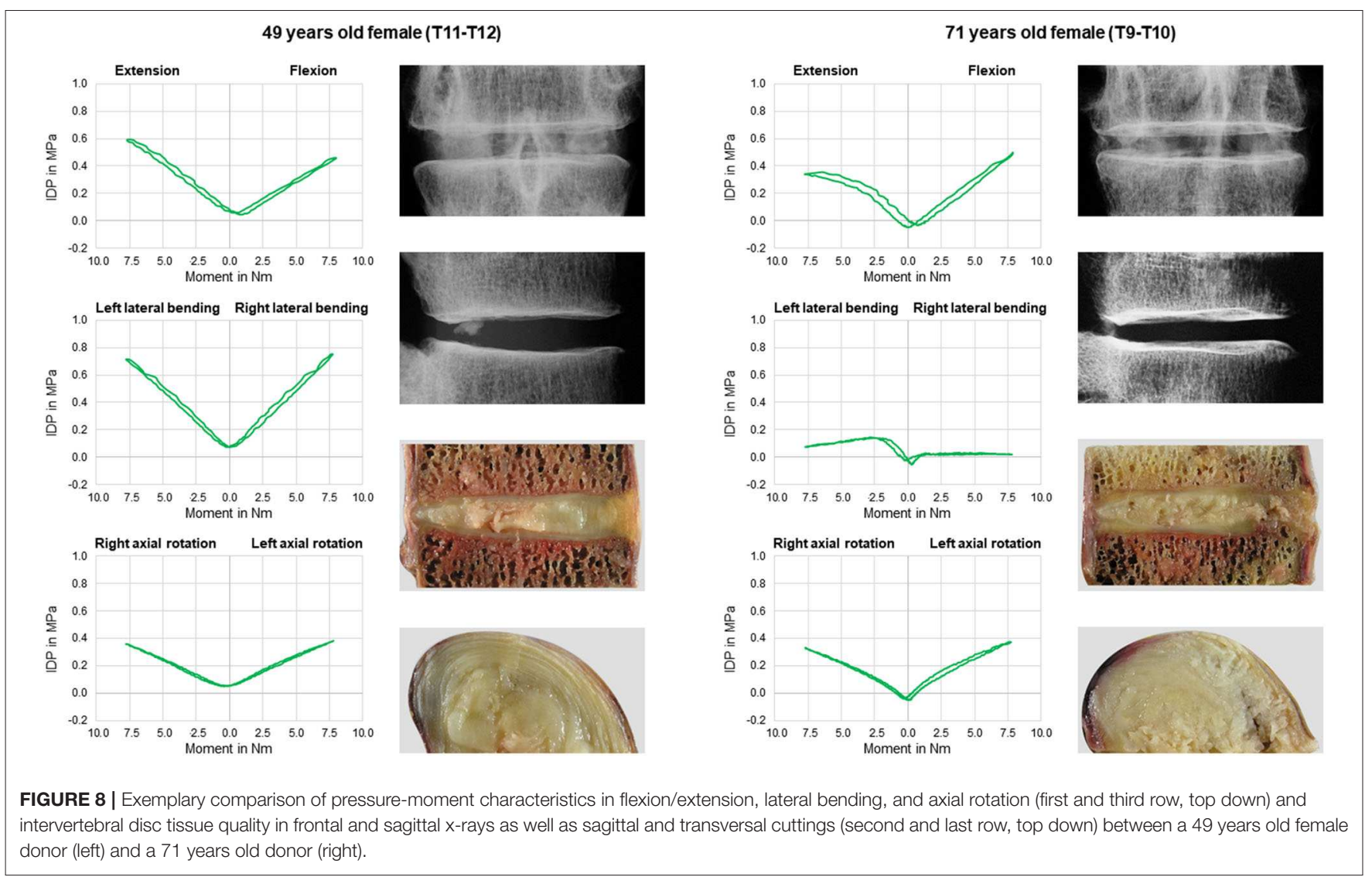

average thoracic spinal motion segments. Nevertheless, the effect of intervertebral disc degeneration on the intradiscal pressure of the thoracic spine represents an important research question, which should be further investigated in future studies.

Previous investigations on the intradiscal pressure of the thoracic spine are limited to few in vitro studies using polysegmental test setups (Cheng et al., 2015; Anderson et al., 2016, 2018; Metzger et al., 2016) and one in vivo study (Polga et al., 2004). While Cheng et al. did not report absolute pressure values and Anderson et al. solely investigated the effect of follower loading on the intradiscal pressure at T4-T5 and T8T9 levels, Metzger et al. found slightly higher average pressure values at T7-T8 level compared to the present study. Mean pressure values of Metzger et al., however, were within the variation range of the present study and exhibited similar pressure behavior with respect to the different motion directions, including pressure values being highest in flexion (Table 2). Anderson et al. (2018) furthermore identified increased pressuremoment slope after rib cage removal, indicating a stabilizing effect of the rib cage structures, which has to be considered when interpreting the results of the present study, where the anterior rib cage structures were neglected. Moreover, pressure-moment slopes were generally higher at T4-T5 level compared to T8T9 level in all motion directions, which can be attributed to the use of an additional compressive follower load of $400 \mathrm{~N}$ in this study. In an in vivo study, Polga et al. measured the intradiscal pressure in mid- (T6-T8) and lower (T9-T11) thoracic spinal levels. They detected pressure values of about $0.3 \mathrm{MPa}$ in the mid- and of about $0.2 \mathrm{MPa}$ in the lower thoracic spine in prone position, presumably resulting from low muscular activity in axial compression direction, while in both upright sitting and standing, the intradiscal pressure increased to about 1.0 MPa in the mid- and to about $0.9 \mathrm{MPa}$ in the lower thoracic spine. During bending and twisting movements of the participants, however, Polga et al. found increasing intradiscal pressure values from the mid- to the lower thoracic spine. Furthermore, the pressure values of Polga et al. were significantly higher compared to the values of a previous study on the lumbar spine in upright standing position, but significantly lower when compared to forward flexed position while holding a weight of $20 \mathrm{~kg}$ (Nachemson and Elfström, 1970). The same trend was also found compared to a further in vivo study on the lumbar spine with one participant (Wilke et al., 1999). Therefore, it might be concluded that in vivo, the intradiscal pressure decreases along the thoracolumbar spine in sole upright position, whereas the pressure increases along the thoracolumbar spine in bending or twisting positions. Comparing these findings with the combined data of the present in vitro study as well as previous in vitro studies, investigating intradiscal pressure in the cervical spine (Pospiech et al., 1999; Dmitriev et al., 2005; Kretzer et al., 2012; Barrey et al., 2015; Liu et al., 2016; Welke et al., 2016; Bell et al., 2018) and lumbar spine (Wilke 


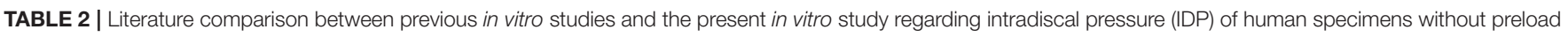
in different motion directions depending on segmental levels and applied moment.

\begin{tabular}{|c|c|c|c|c|c|c|c|}
\hline References & Level(s) & $\begin{array}{l}\text { Intrinsic IDP } \\
(0 \mathrm{Nm}) \text { in } \mathrm{MPa}\end{array}$ & Moment in $\mathrm{Nm}$ & $\begin{array}{l}\text { Flexion IDP in } \\
\text { MPa }\end{array}$ & $\begin{array}{l}\text { Extension } \\
\text { IDP in MPa }\end{array}$ & $\begin{array}{l}\text { Lateral bending } \\
\text { IDP in MPa }\end{array}$ & $\begin{array}{l}\text { Axial rotation } \\
\text { IDP in MPa }\end{array}$ \\
\hline Liu et al. (2016)* & C2-C6 & - & 1.5 & $0.2-0.3$ & $0.1-0.2$ & 0.2 & 0.2 \\
\hline Kretzer et al. (2012)\# & $\begin{array}{l}\text { C2-C3, } \\
\text { C6-C7, } \\
\text { C7-T1 }\end{array}$ & - & 2.0 & $0.1-0.4$ & $0.1-0.4$ & $0.1-0.5$ & - \\
\hline Barrey et al. (2015)* & C3-C5 & $0.0-0.1$ & 2.0 & 0.7 & $0.2-0.4$ & $0.0-0.2$ & $0.1-0.2$ \\
\hline Pospiech et al. (1999)\# & $\begin{array}{l}\text { C3-C4, } \\
\text { C5-C6 }\end{array}$ & - & 0.5 & $0.2-0.3$ & $0.2-0.3$ & 0.2 & $0.2-0.3$ \\
\hline Bell et al. (2018)* & C4-C6 & $0.1-0.2$ & 2.0 & $0.5-0.9$ & $0.3-0.4$ & - & - \\
\hline Welke et al. (2016)* & $\begin{array}{l}\text { C4-C5, } \\
\text { C6-C7 }\end{array}$ & - & 2.0 & 0.5 & 0.5 & 0.3 & 0.2 \\
\hline Dmitriev et al. (2005)* & $\begin{array}{l}\text { C4-C5, } \\
\text { C6-C7 }\end{array}$ & - & 5.0 & $0.5-1.1$ & $0.5-1.1$ & 0.3 & $0.2-0.3$ \\
\hline \multirow[t]{3}{*}{ Present study"\# } & $\mathrm{T} 1-\mathrm{T} 12$ & -0.1 to 0.2 & 2.5 & $0.1-0.5$ & $0.0-0.4$ & -0.1 to 0.5 & $0.1-0.3$ \\
\hline & & & 5.0 & $0.2-0.8$ & $0.0-0.4$ & -0.1 to 0.7 & $0.2-0.5$ \\
\hline & & & 7.5 & $0.3-1.1$ & $0.0-0.5$ & -0.1 to 0.8 & $0.3-0.6$ \\
\hline Metzger et al. (2016) & T7-Т8 & - & 4.0 & 0.9 & 0.7 & 0.6 & 0.6 \\
\hline Gao et al. (2011)* & $\begin{array}{l}\text { L3-L4, } \\
\text { L5-S1 }\end{array}$ & - & 10.0 & 0.2 & 0.1 & 0.1 & 0.1 \\
\hline Schmoelz et al. (2006)\# & L3-L4 & 0.1 & 10.0 & 0.3 & 0.3 & 0.3 & 0.2 \\
\hline Molz et al. (2003)* & L3-L4 & - & 10.0 & 0.1 & 0.1 & 0.0 & 0.1 \\
\hline \multirow[t]{4}{*}{ Heuer et al. (2007) } & L4-L5 & 0.0 & 2.5 & 0.1 & 0.1 & - & - \\
\hline & & & 5.0 & 0.2 & 0.1 & - & - \\
\hline & & & 7.5 & 0.3 & 0.2 & - & - \\
\hline & & & 10.0 & 0.3 & 0.2 & - & - \\
\hline Rohlmann et al. (2001)* & L4-L5 & $0.0-0.1$ & 7.5 & 0.1 & 0.1 & 0.1 & 0.1 \\
\hline Wilke et al. (1996)* & L4-L5 & 0.1 & 3.75 & 0.2 & 0.2 & 0.2 & 0.2 \\
\hline
\end{tabular}

*, Mean values reported; \#, Median values reported.

et al., 1996; Rohlmann et al., 2001; Molz et al., 2003; Schmoelz et al., 2006; Heuer et al., 2007; Gao et al., 2011) without axial preload, a different intradiscal pressure distribution can be observed. While showing almost consistent intrinsic intradiscal pressure along the spine, the intradiscal pressure tends to decrease along the spine under pure moment application in all motion directions, especially when seen in relation to the applied moment (Table 2). This might indicate that additional axial preload alters the intradiscal pressure distribution along the spine, which should be considered in future experimental testing as well as in numerical model development. Moreover, additional compressive preload affects the pressure-moment characteristics, as previously shown for the lumbar spine (Rohlmann et al., 2001), especially leading to increased intrinsic pressure, which has to be taken into account when comparing the in vitro data of the present study to in vivo data and when validating numerical models. Testing without additional compressive load therefore represents a major limitation of the present study. Nevertheless, the data of the present study is essential for the validation of numerical models of the thoracic spine due to its clearly defined boundary conditions and therefore highly reproducible data. Previous investigations suggest a $400 \mathrm{~N}$ follower preload in order to create physiological intradiscal pressure values in the thoracic spine (Anderson et al., 2016), while producing potential, hardly controllable artifacts due to coupling and clamping effects at the same time. Moreover, follower load was shown to significantly decrease the flexibility and to alter the threedimensional motion behavior of the thoracic spine (Liebsch et al., 2018), leading to additional boundary conditions for numerical models. Furthermore, preloading of the specimen might affect the intradiscal pressure measurement due to the distinct decrease of intervertebral disc height, which is lowest in the thoracic spine (Pooni et al., 1986). When using the herein presented data for the validation of a numerical model of the thoracic spine, the costovertebral joints have to be considered due to the presence of the posterior sections of the ribs in the present study. These were left intact because of their stabilizing effect on thoracic spinal motion segments (Liebsch et al., 2017) and thus their potential influence on the intradiscal pressure. Another limitation of the present study is that possible effects of the sensor entry point in the anterior part of the intervertebral disc cannot be fully excluded and may have caused small measuring artifacts especially in flexion direction. However, all tested specimens in the present study showed adequate anterior disc height, suggesting only minimal effects of the sensor entry point.

In conclusion, a large dataset regarding intradiscal pressure values of the human thoracic spine was generated. This dataset 
can be used as comparative data for future in vitro studies as well as for the validation process of numerical models of the thoracic spine.

\section{DATA AVAILABILITY STATEMENT}

All datasets presented in this study are included in the article/Supplementary Material.

\section{ETHICS STATEMENT}

The use of human specimens was approved by the ethical committee board of the University of Ulm, Germany, in November 2014 (No. 302/14). The specimens were acquired from the body donation organizations Anatomy Gifts Registry program (AGR, Hanover, Maryland, USA) and Science Care (Science Care Inc., Phoenix, Arizona, USA), which declared that written informed consent of the donors was obtained prior to decease.

\section{REFERENCES}

Adams, M.A., Green, T.P., and Dolan, P. (1994). The strength in anterior bending of lumbar intervertebral discs. Spine 19, 2197-2203. doi: 10.1097/00007632-199410000-00014

Adams, M. A., McNally, D. S., and Dolan, P. (1996). 'Stress' distributions inside intervertebral discs. The effects of age and degeneration. J. Bone Joint Surg. Br. 78, 965-972. doi: 10.1302/0301-620X.78B6.0780965

Anderson, D. E., Mannen, E. M., Sis, H. L., Wong, B. M., Cadel, E. S., Friis, E. A., et al. (2016). Effects of follower load and rib cage on intervertebral disc pressure and sagittal plane curvature in static tests of cadaveric thoracic spines. J. Biomech. 49, 1078-1084. doi: 10.1016/j.jbiomech.2016.02.038

Anderson, D. E., Mannen, E. M., Tromp, R., Wong, B. M., Sis, H. L., Cadel, E. S., et al. (2018). The rib cage reduces intervertebral disc pressures in cadaveric thoracic spines by sharing loading under applied dynamic moments. J. Biomech. 70, 262-266. doi: 10.1016/j.jbiomech.2017.10.005

Barrey, C., Rousseau, M. A., Persohn, S., Campana, S., Perrin, G., and Skalli, W. (2015). Relevance of using a compressive preload in the cervical spine: an experimental and numerical simulating investigation. Eur. J. Orthop. Surg. Traumatol. 25, 155-165. doi: 10.1007/s00590-015-1625-2

Bell, K. M., Yan, Y., Hartman, R. A., and Lee, J. Y. (2018). Influence of follower load application on moment-rotation parameters and intradiscal pressure in the cervical spine. J. Biomech. 76, 167-172. doi: 10.1016/j.jbiomech.2018.05.031

Cheng, I., Sundberg, E. B., Iezza, A., Lindsey, D. P., and Riew, K. D. (2015). Biomechanical determination of distal level for fusions across the cervicothoracic junction. Global Spine J. 5, 282-286. doi: 10.1055/s-0035-1546418

Dmitriev, A. E., Cunningham, B. W., Hu, N., Sell, G., Vigna, F., and McAfee, P. C. (2005). Adjacent level intradiscal pressure and segmental kinematics following a cervical total disc arthroplasty: an in vitro human cadaveric model. Spine 30, 1165-1172. doi: 10.1097/01.brs.0000162441.23824.95

Gao, S. G., Lei, G. H., He, H. B., Liu, H., Xiao, W. F., Wen, T., et al. (2011). Biomechanical comparison of lumbar total disc arthroplasty, discectomy, and fusion: effect on adjacent-level disc pressure and facet joint force. J. Neurosurg. Spine 15, 507-514. doi: 10.3171/2011.6.SPINE11250

Goh, S., Tan, C., Price, R. I., Edmondston, S. J., Song, S., Davis, S., et al. (2000). Influence of age and gender on thoracic vertebral body shape and disc degeneration: an MR investigation of 169 cases. J. Anat. 197, 647-657. doi: 10.1046/j.1469-7580.2000.19740647.x

Heuer, F., Schmidt, H., Claes, L., and Wilke, H. J. (2007). Stepwise reduction of functional spinal structures increase vertebral translation and intradiscal pressure. J. Biomech. 40, 795-803. doi: 10.1016/j.jbiomech.2006.03.016

\section{AUTHOR CONTRIBUTIONS}

H-JW: funding acquisition, discussion, and manuscript review. $\mathrm{AH}$ : study design, specimen preparation, and experimental testing. KW: specimen preparation and experimental testing. CL: data analysis, discussion, and manuscript preparation. All authors contributed to the article and approved the submitted version.

\section{ACKNOWLEDGMENTS}

The authors gratefully acknowledge funding from the German Research Foundation (DFG, project WI1352/20-2).

\section{SUPPLEMENTARY MATERIAL}

The Supplementary Material for this article can be found online at: https://www.frontiersin.org/articles/10.3389/fbioe. 2020.00614/full\#supplementary-material

Koeller, W., Meier, W., and Hartmann, F. (1984). Biomechanical properties of human intervertebral discs subjected to axial dynamic compression. A comparison of lumbar and thoracic discs. Spine 9, 725-733. doi: 10.1097/00007632-198410000-00013

Kretzer, R. M., Hsu, W., Hu, N., Umekoji, H., Jallo, G. I., McAfee, P. C., et al. (2012). Adjacent-level range of motion and intradiscal pressure after posterior cervical decompression and fixation: an in vitro human cadaveric model. Spine 37, E778-E785. doi: 10.1097/BRS.0b013e31824780b8

Liebsch, C., Graf, N., Appelt, K., and Wilke, H. J. (2017). The rib cage stabilizes the human thoracic spine: An in vitro study using stepwise reduction of rib cage structures. PLoS ONE 12:e0178733. doi: 10.1371/journal.pone.0178733

Liebsch, C., Graf, N., and Wilke, H. J. (2018). The effect of follower load on the intersegmental coupled motion characteristics of the human thoracic spine: an in vitro study using entire rib cage specimens. J. Biomech. 78, 36-44. doi: 10.1016/j.jbiomech.2018.06.025

Liu, Q., Guo, Q., Yang, J., Zhang, P., Xu, T., Cheng, X., et al. (2016). Subaxial cervical intradiscal pressure and segmental kinematics following atlantoaxial fixation in different angles. World Neurosurg. 87, 521-528. doi: 10.1016/j.wneu.2015.09.025

Metzger, M. F., Robinson, S. T., Svet, M. T., Liu, J. C., and Acosta, F. L. (2016) Biomechanical analysis of the proximal adjacent segment after multilevel instrumentation of the thoracic spine: do hooks ease the transition? Global Spine J. 6, 335-343. doi: 10.1055/s-0035-1563611

Molz, F. J., Partin, J. I., and Kirkpatrick, J. S. (2003). The acute effects of posterior fusion instrumentation on kinematics and intradiscal pressure of the human lumbar spine. J. Spinal Disord Tech. 16, 171-179. doi: 10.1097/00024720-200304000-00009

Nachemson, A. (1959). Measurement of intradiscal pressure. Acta Orthop. Scand. 28, 269-289. doi: 10.3109/17453675908988632

Nachemson, A. (1960). Lumbar intradiscal pressure. Experimental studies on post-mortem material. Acta Orthop. Scand. Suppl. 43, 1-104. doi: 10.3109/ort.1960.31.suppl-43.01

Nachemson, A., and Elfström, G. (1970). Intravital dynamic pressure measurements in lumbar discs. A study of common movements, maneuvers and exercises. Scand J. Rehabil. Med. Suppl. 1, 1-40.

Nachemson, A. L., Schultz, A. B., and Berkson, M. H. (1979). Mechanical properties of human lumbar spine motion segments. Influence of age, sex, disc level, and degeneration. Spine 4, 1-8. doi: 10.1097/00007632-19790100000001

Panjabi, M., Brown, M., Lindahl, S., Irstam, L., and Hermens, M. (1988). Intrinsic disc pressure as a measure of integrity of the lumbar spine. Spine 13, 913-917. doi: 10.1097/00007632-198808000-00008 
Polga, D. J., Beaubien, B. P., Kallemeier, P. M., Schellhas, K. P., Lew, W. D., Buttermann, G. R., et al. (2004). Measurement of in vivo intradiscal pressure in healthy thoracic intervertebral discs. Spine 29, 1320-1324. doi: 10.1097/01.BRS.0000127179.13271.78

Pooni, J. S., Hukins, D. W., Harris, P. F., Hilton, R. C., and Davies, K. E. (1986). Comparison of the structure of human intervertebral discs in the cervical, thoracic and lumbar regions of the spine. Surg. Radiol. Anat. 8, 175-182. doi: 10.1007/BF02427846

Pospiech, J., Stolke, D., Wilke, H. J., and Claes, L. E. (1999). Intradiscal pressure recordings in the cervical spine. Neurosurgery 44, 379-384. doi: 10.1097/00006123-199902000-00078

Rohlmann, A., Neller, S., Claes, L., Bergmann, G., and Wilke, H. J. (2001). Influence of a follower load on intradiscal pressure and intersegmental rotation of the lumbar spine. Spine 26, E557-E561. doi: 10.1097/00007632-200112150-00014

Schmoelz, W., Huber, J. F., Nydegger, T., Claes, L., and Wilke, H. J. (2006). Influence of a dynamic stabilisation system on load bearing of a bridged disc: an in vitro study of intradiscal pressure. Eur. Spine J. 15, 1276-1285. doi: $10.1007 / \mathrm{s} 00586-005-0032-5$

Stefanakis, M., Luo, J., Pollintine, P., Dolan, P., and Adams, M. A. (2014). ISSLS Prize winner: mechanical influences in progressive intervertebral disc degeneration. Spine 39, 1365-1372. doi: 10.1097/BRS.0000000000000389

Welke, B., Schwarze, M., Hurschler, C., Book, T., Magdu, S., and Daentzer, D. (2016). In vitro investigation of a new dynamic cervical implant: comparison to spinal fusion and total disc replacement. Eur. Spine J. 25, 2247-2254. doi: 10.1007/s00586-015-4361-8

Wilke, H.J., Grundler, S., Ottardi, C., Mathew, C.E., Schlager, B., and Liebsch, C. (2020). In vitro analysis of thoracic spinal motion segment flexibility during stepwise reduction of all functional structures. Eur. Spine J. 29, 179-185. doi: 10.1007/s00586-019-06196-7
Wilke, H. J., Claes, L., Schmitt, H., and Wolf, S. (1994). A universal spine tester for in vitro experiments with muscle force simulation. Eur. Spine J. 3, 91-97. doi: 10.1007/BF02221446

Wilke, H. J., Herkommer, A., Werner, K., and Liebsch, C. (2017). In vitro analysis of the segmental flexibility of the thoracic spine. PLOS ONE 12:e0177823. doi: 10.1371/journal.pone. 0177823

Wilke, H. J., Neef, P., Caimi, M., Hoogland, T., and Claes, L. E. (1999). New in vivo measurements of pressures in the intervertebral disc in daily life. Spine 24, 755-762. doi: 10.1097/00007632-199904150-00005

Wilke, H. J., Wenger, K., and Claes, L. (1998). Testing criteria for spinal implants: recommendations for the standardization of in vitro stability testing of spinal implants. Eur. Spine J. 7, 148-154. doi: 10.1007/s0058600 50045

Wilke, H. J., Wolf, S., Claes, L. E., Arand, M., and Wiesend, A. (1996). Influence of varying muscle forces on lumbar intradiscal pressure: an in vitro study. J. Biomech. 29, 549-555. doi: 10.1016/0021-9290(95) 00037-2

Conflict of Interest: The authors declare that the research was conducted in the absence of any commercial or financial relationships that could be construed as a potential conflict of interest.

Copyright () 2020 Wilke, Herkommer, Werner and Liebsch. This is an open-access article distributed under the terms of the Creative Commons Attribution License (CC $B Y)$. The use, distribution or reproduction in other forums is permitted, provided the original author(s) and the copyright owner(s) are credited and that the original publication in this journal is cited, in accordance with accepted academic practice. No use, distribution or reproduction is permitted which does not comply with these terms. 